\title{
Comparative Analysis of Methods for Evaluating Efficiency of Regional Investment Policy
}

\author{
Liliya Nevyantseva*, and Nataliya Vlasova \\ Ural State University of Economics, 620990 Ekaterinburg, Russia
}

\begin{abstract}
The article highlights the issues of methodological tools for evaluating the efficiency of regional investment policy. The article provides international experience of investment policy evaluation and presents the evolution of approaches to evaluating the investment policy of Russian regions and the investment climate. Four approaches are outlined on the basis of domestic methods analyzed: cost-result, rating, integral and complex (qualitative and quantitative). The approach based on evaluation of investment performance and the costs incurred is widely used in Russia. The conclusions are drawn from the research findings: the existing approaches to evaluating the efficiency of investment policy at the regional level have disadvantages and use restrictions. The concluding part contains outlined actions aimed at improving the tools and methods for evaluating the efficiency of investment policy of regional units.
\end{abstract}

\section{Introduction}

Improving the efficiency of the regional investment policy (hereinafter-RIP) is particularly important for developing all subjects of the Russian Federation. In order to achieve new economic goals and objectives set by Strategies for spatial and socio-economic development it is necessary to attract investment to all regions of the Russian Federation and implement regional investment programs maximally in the short and long term. Effective management of investment processes is integral to successful achievement of strategic development goals; investment policy performance is a basis for developing strategies for social and economic development of the country and regions.

However, common approaches to assessing investment policy performance implemented at both the Federal and sub-Federal levels have not been developed in foreign and domestic science and public administration practice. In particular, there is no complex system for managing investment activities in social and economic systems, and the appropriate regulatory and methodological foundations haven't been formed yet. It determines the relevance of the issue under consideration which consists in developing accurate and scientifically proven methods for evaluating the efficiency and directions of improving investment policy which makes it possible for the regions to adapt to the changing conditions of spatial development on time.

\footnotetext{
* Corresponding author: Inevyantseva@yandex.ru
} 


\section{Materials and Methods}

In the course of the research the authors analyze the methodological approaches to evaluating the efficiency of investment policy implementation in regional social and economic systems. The purpose of the work is a comparative analysis of methodological approaches to assessing investment policy performance at the regional level, identifying advantages and use restrictions in practice. The research materials include scientific and practical articles, findings of foreign and Russian scientists-economists, and data provided by rating agencies.

The article is prepared using the main research methods: analysis, synthesis, comparison and generalization of the results.

\section{Results and Discussions}

The analysis of foreign literature [1-5] on investment development of the country and particular territories shows that the investment climate is an intensively studied area while investment policy, analysis and efficiency evaluation is a less studied area. The investment climate is considered in regional development as an integral indicator of the "quality" of the investment environment in a certain territory. Therefore, the level of investment attractiveness of the region is often assessed along with the analysis. Most foreign methods of assessing the investment policy of the country and particular territorial entities are based on evaluation findings of two components.

Foreign research of evaluating an investment policy dates back to 1909 when the rating agency "Moody's" evaluated investment climate of the country for the first time. In 1916 a similar analysis was conducted by the rating agency "Standard \& Poor's Corporation". In 1924 the agency "Fitch ratings" introduced a special rating scale from AAA to D which is widely used in Russia. In the second half of the XX century the research findings provided by the Harvard Business School (USA) were widely used in public administration on the basis of assessing investment climate on a score-scale. In addition, the German methodology Business Environment Risk Intelligence was also applied on the basis of 15 indices using the score-scale of the Harvard Business School.

Transformation of economic relations and transition of some countries to "market rails" resulted in significant changes in attracting investments in the late 1980s and early 1990s. Subsequently, new methodological approaches to assessing investment parameters were to be found. "The Wall Street Journal Europe's and Multinational Business" experts developed rather simple methods for assessing investment attractiveness that meet the market needs and take into account the influence of various factors.

As a result, the World Bank developed a new methodology for assessing the investment climate of market economies. It was based on the analysis of macroeconomic and structural indicators of business environment which covers small- and medium-sized entities. The World Bank's methodology was widely accepted by all countries of the world. It was adapted to assessing the efficiency of government activities to create a favorable investment environment but it didn't take into account the assessment of economic indicators and possible risks. In 1995 the Institute of Advanced Studies developed a new tool for assessing the investment climate of regions on the basis of identified regional investment risks. It should be noted that unlike the World Bank's methodology, this methodology was focused on regional direction on the basis of identified risks and threats.

Unlike international practice which is mainly focused on assessing the country's (national) investment climate and other investment parameters, similar studies conducted by Russian scientists and expert agencies have a regional perspective. It is due to the existing interregional differences and the federal structure of the state. Foreign techniques 
were successfully tested in Russia and were adapted to the economic peculiarities of Russian regions, i.e. Institute of Economics RAS evaluation of methodology of the regional investment climate, analysis of investment features of the Russian regions conducted by A. S. Martynov using the software Datagraf, Council methodology of studying productive forces, etc. Significant scientific and practical contribution to developing instruments for evaluating the regional investment climate has been made by the rating agencies (RAEX Analytics, National rating Agency, Agency for strategic initiatives, and RIA Rating, ACRA, etc.).

From the standpoint of Russian economic and historical development, methodological approaches to evaluating the investment policy and the investment climate underwent some changes caused by current trends (table.1).

Table 1. Evolution of approaches to the analysis and evaluation of investment policy and investment climate of RF regions $[11,12]$

\begin{tabular}{|c|c|}
\hline Period & Specific features of investment parameters evaluation in Russia \\
\hline $\begin{array}{l}\text { Until the mid- } 80 \text { s of the } \\
\text { XX century }\end{array}$ & $\begin{array}{l}\text { In the period of command economy the main paradigm of an economic } \\
\text { model was the planning of national economy, the authorities applied } \\
\text { indicators of capital investment performance to identify the level of } \\
\text { regional development. }\end{array}$ \\
\hline $\begin{array}{l}\text { The second half of the } \\
\text { 1980s-the beginning. } \\
\text { 1990's. }\end{array}$ & $\begin{array}{l}\text { Studying the investment climate of the country and regions most domestic } \\
\text { economists developed scientific recommendations for increasing the } \\
\text { economic efficiency of capital construction in this period. Foreign methods } \\
\text { of assessing the investment favorability of the territory were of particular } \\
\text { interest. }\end{array}$ \\
\hline middle $1990 \mathrm{~s}-2000 \mathrm{~s}$ & $\begin{array}{l}\text { In the period of "soft" federal investment policy of the 1990s the } \\
\text { investment management performance of Russian Federation entities was } \\
\text { directly determined by the quality of the regional investment management } \\
\text { (successful practice: liberal economic policy of Nizhny Novgorod region } \\
\text { and policy "soft entering the market" of the Republic of Tatarstan; negative } \\
\text { example of a conservative policy of Ulyanovsk region). }\end{array}$ \\
\hline $\begin{array}{l}\text { "Sustainable economic } \\
\text { growth" (2000-2008) }\end{array}$ & $\begin{array}{l}\text { As the centralization of authorities in most regions of the Russian } \\
\text { Federation was enhanced, investment attraction and the efficiency of } \\
\text { investment policy were in relation to objective factors. The factor of foreign } \\
\text { investment started to play an important part in assessing the efficiency of } \\
\text { investment policy }\end{array}$ \\
\hline $\begin{array}{l}\text { "Slumping economy" } \\
\text { (2009-2012 гг.) }\end{array}$ & $\begin{array}{l}\text { In } 2008-2011 \text { the volume of foreign direct investment decreased } \\
\text { dramatically in all Russian regions even in the central ones. As in the pre- } \\
\text { crisis period, the efficiency of investment policy depends on objective } \\
\text { factors of the regional economy }\end{array}$ \\
\hline $\begin{array}{l}\text { "Post-crisis economy" } \\
\text { (2013-present) }\end{array}$ & $\begin{array}{l}\text { Research issues of regional investment policy are related to an assessment } \\
\text { of the investment climate. The research is based on a comparative regional } \\
\text { analysis based on official statistics and surveys of the business community. }\end{array}$ \\
\hline
\end{tabular}

The analysis of Russian scientific publications [6-13] on the development and testing of methodological tools for assessing the efficiency of investment policy at the sub-federal level made it possible to identify four approaches to forming the direction of assessing the efficiency of regional policy: cost-result, rating, integral and complex (qualitative and quantitative).

Let's consider the essence and specific features of the selected methods outlined in the above-mentioned approaches.

According to most methodological approaches proposed by Russian scientists the efficiency of the implemented investment policy is evaluated on the basis of the dynamics of two main factors - the volume of investment in fixed assets and the gross regional product, i,e., based on the analysis of the costs incurred and the economic effect in the form of gross product. For example, O. V. Kiseleva believes that "the evaluation of the efficiency of investment management at the regional level should be based on the principle of cost recovery and investment" [7]. In this regard, the author proposes a methodology for 
assessing the efficiency of RIP based on statistical indices that can determine the quality (level) of social and economic development of the territory. The essence of the methodology lies in comparing the rate of the gross regional product and the growth rate of investment in fixed assets [7].

Another researcher offers a more extensive list of criteria for assessing the efficiency of RIP, i.e.: growth of the gross regional product as a whole and per capita, growth rate of investment in fixed assets and the increased share of foreign investment in the total volume of investment in fixed assets within a certain period [8].

These methods are characterized by a relative simplicity of evaluation and follow-up analysis of performance indicators. These methodological approaches are versatile and available for evaluating the regional investment policy of different types and levels of development. As far as the composition of the indicator system is concerned, the approaches in question have significant drawbacks. The quantitative indicators for assessing the investment policy performance such as the increase in gross regional product, per capita income and investment in fixed assets do not entirely indicate the efficiency of the investment policy implemented by regional authorities. As a rule, changes in these indicators are the result of the economic policy implemented by the subject of the Russian Federation as a whole, and it is quite problematic to determine the contribution of the investment direction.

The most popular methods in the Russian scientific literature for assessing the efficiency of RIP are based on various rating lists (for example, the Expert RA ratings and the National Rating of Investment Attractiveness of the subjects of the Russian Federation). Supporters of this approach believe that "the ratings are a qualitative evaluation of efficiency of regional investment policy, and integral estimates make it possible to determine the level of investment policy implemented by the regional authorities which is partially reflected in this rating components that define the investment climate" [9].

In our opinion, these methods are oblique to investment policy, and the evaluation of efficiency, rating analysis can only be applied indirectly. G. A. Untura also points out the methodological gaps of this toolkit saying that "there is no statistical correlation between the ratings of investment potential and investment risk (according to the Expert RA method), and real investments in the regions of Russia"10]. O. I. Kondratenko supposes that the national rating of investment attractiveness of the Russian Federation subjects has some drawbacks. The author notes that "as the rating and target models are formed on the basis of performance indicators of attracting investment to the most prosperous Russian regions, 23 subjects of the Russian Federation filed an appeal against the rating results of and the implementation of target models in 2017, 42 regions in 2018, and 65 regions in 2019» [11].

N. A. Moskvitina offers to implement an integral system of coefficients to evaluate the efficiency of RIP. In the author's opinion, "the weighted average indicator that determines the efficiency of the support measures provided to enterprises in the region makes it possible to assess the overall efficiency of investment policy implemented in the subject of the Russian Federation" [12]. The author uses 3 parameters that act as performance indicators of an enterprise: budget (regional) efficiency, social and economic efficiency and innovation component. The input of each parameter to the integral coefficient is $0.4,0.4$ and 0.2. The three indicators include sub-parameters which have a certain weighting factor. Benefits are provided to the company on the basis of evaluation, and the degree of investment policy implementation in the region can be considered effective if the final coefficient is greater than or equal to 0.4 .

Although the author's methodology offers a system of indicators that assesses the performance of enterprises, it can also be implemented to evaluate the efficiency of social and economic systems at various levels (the national economy as a whole and the economy 
of regions in particular). In our opinion, this methodology is not fully adapted to evaluate the efficiency of investment policy as it does not take into account direct factors of investment activity. In addition, the collection and processing of data on the activities of regional enterprises is a difficult procedure to be conducted because all the relevant information isn't published in open sources. The advantage of the method is the versatility of the evaluation as the value of the integral indicator depends on three parameters of the enterprise's activity in the region but in this regard the author is recommended to justify the value of the weight coefficients.

Domestic research works apply a complex approach to evaluate the efficiency of RIP using quantitative and qualitative indicators. The methodology proposed by A. G. Nazarov is considered as an example. The author identifies the following groups of indicators for assessing RIP: special elements in the implementation of investment policy (for example, investment declarations, a special body for investment activation, a plan for investment and infrastructure facilities, approved territorial planning schemes, regulatory legal acts on the protection of investors' rights, accessible infrastructure, a bilingual Internet portal, monitoring systems, financial support, etc.); quantifiable characteristics of investment policy (for example, the rate of payment for technological connection, etc.); indicators of investment capital inflow (ratio of fixed capital investment to gross regional product); results of surveys on entrepreneurs and investors (at the regional and country level). As for the first group of indicators, the criterion for assessing the investment policy performance of regional authorities is to provide the answer "yes", i.e. a particular measure aimed to support investors. The second, third and fourth groups are supposed to have a deviation for the better from the average value of the indicator for the Russian regions [13].

A comprehensive method of evaluating the efficiency of RIP is proposed by N. A. Serova. To evaluate the investment policies the author proposes to use a general criteria of assessing authorities' activities of the Russian Federation subjects sustainable dynamics of gross regional product and investments in fixed capital per capita, increased number of small businesses and the turnover, increased regional budget revenues, share of investment in gross regional product and the volume of foreign investments per capita. The group of quality indicators is to assess the level of public-private partnerships, the number of implemented elements involved in the Standard of activities of executive bodies of the RF subjects on ensuring a favorable investment climate, and undertaken regional financial support measures for investors and entrepreneurs [14].

Applying the N. A. Serova's and A. G. Nazarov's methods for evaluating the efficiency of RIP investors and other interested parties can obtain objective information on the conditions for implemented investment activities in the target territory and issues on financial support for implemented investment projects, tax and customs guarantees, general requirements for industry investment, availability of business infrastructure and design, construction and consulting firms for the implementing projects, etc. In addition, the advantage of A. G. Nazarov's method is entrepreneurs' opinion taken into consideration despite the subjective nature of the indicator. It contributes to a close-to-reality assessment of regional investment management and determines the availability and use restrictions of tools for implementing an investment policy.

However, these methods have a number of disadvantages: extensive list of indicators and unreasonable application makes the technique cumbersome and time consuming; complexity of some indicators, original data that is not presented in the Russian information system. Indicators are controversial and are not comparable which restricts the use of techniques in the regional management.

Thus, the results of the analysis show that all the analyzed approaches have certain disadvantages and use restrictions. In this regard, economics is to develop a modern methodology for assessing the efficiency of regional investment policies. This methodology 
is to have a complex character and consider the operating parameters of different regional economies in a single system.

\section{Conclusions}

Analysis and comparison of methods for evaluating the efficiency of RIP shows that they differ in the methodology and the composition of performance indicators. The methods in question include a different number of quantitative and qualitative indicators and various groups of factors that affect the investment policy. In addition, each method differs from the alternative methods in the scope of data and measuring methods, methods of analyzing the data base. The methodological tools used to assess investment policy include integral assessments, factors and risks assessment, rating analysis, analysis of statistical data, targetperformance comparison, and subjective assessments.

When developing a methodology for evaluating the efficiency of RIP it is necessary to follow the principles for evaluating the policy performance: complexity, balanced assessments, consistency, operational indicators, maximum efficiency, time factor, competence, transparency, timeliness. To develop the author's methodology we plan to use the principles of flexibility and versatility applicable to any object of assessment. To improve the methodological tools for evaluating the investment policy performance we consider it appropriate to use a comprehensive approach that includes a selected set of quantitative and qualitative indicators for practical analysis and conclusions. At the same time, the existing methods are to expand the criteria for implementing a systematic multifactor assessment. We consider the international practice to be reliable when we test the efficiency of implemented of RIP in relation to the investment climate evaluation (shortterm analysis) and investment attractiveness (long-term analysis). In conclusion, it should be noted that the current investment climate should be evaluated objectively and social and economic changes in the territory should be monitored to efficiently implement RIP.

\section{References}

1. R. Huggins, B. Morgan, N. Williams, Journal of Small Business and Enterprise Development, 22(3) (2015)

2. Fratesi Ugo, G. Fiona, Wishlade The impact of European Cohesion Policy in different contexts, Regional Studies (2017)

3. John Bradley, Timo Mitze, Edgar Morgenroth, Gerhard Untiedt, An Integrated MicroMacro (IMM) approach to the evaluation of large-scale public investment programs: The case of EU structural funds, ESRI Working Paper, The Economic and Social Research Institute (ESRI), 167 (2005)

4. Azad Singh Bali, Giliberto Capano, M. Ramesh, Policy and Society, 1 (2019)

5. Ishani Mukherjee, Azad Singh Bali, Policy Design and Practice, 2(2) (2019)

6. O.B. Sheveleva, M.K. Nacheva, Innovations, 2(160), 45 (2012)

7. O.V. Kiseleva, Scientific and technical statements of the St. Petersburg State Polytechnic University, Economic sciences, 4(175), 53 (2013)

8. E.N. Novokshonova, Regional economy: theory and practice, 11, 338 (2014)

9. K.V. Krinichansky, In the collection: Russian regions in the focus of change. collection of reports of the X International conference, 907 (2016)

10. G.A. Untura, Region: Economics and Sociology, 1, 200 (2004)

11. O.I. Kondratenko, State Service, 2, 70 (2020) 
12. N.A. Moskvitina, Problems of theory and practice of management, 11, 37 (2018)

13. A.G. Nazarov, Economy and Entrepreneurship, 12 (2), 261 (2014)

14. N.A. Serova, North and Market: Formation of the Economic Order, 5(56), 105 (2017) 